\title{
Short- and long-term outcome of patients with spontaneous echo contrast or thrombus in the left atrial appendage in the era of the direct acting anticoagulants
}

\author{
Julian Felix Backhaus ${ }^{1} \cdot$ Andreas Pflaumbaum $^{1} \cdot$ Christos Krogias $^{2}$ - Fabienne Kreimer ${ }^{1}$. Andreas Mügge ${ }^{1}$. \\ Ralf Gold ${ }^{2} \cdot$ Michael Gotzmann ${ }^{1}$ (D)
}

Received: 28 May 2021 / Accepted: 16 August 2021 / Published online: 26 August 2021

(C) The Author(s) 2021

\begin{abstract}
Background Thrombi and spontaneous echo contrast (SEC) in the left atrial appendage (LAA) are associated with thromboembolic events and poor prognosis. There are very few data on long-term outcome, especially with the use of direct acting anticoagulants (DOAC).

Methods In this retrospective study, all transoesophageal echocardiographies performed at a tertiary care university hospital from 2015 to 2020 were analyzed. All patients with thrombus or SEC in the LAA were included. Medical history, laboratory, echocardiographic parameters and medication at discharge were documented. The primary endpoint of the study was a composite endpoint (all-cause mortality, non-fatal stroke or transient ischaemic attack [TIA], non-fatal systemic embolization, non-fatal major bleeding and non-fatal myocardial infarction).

Results Of a total of 4062 transoesophageal echocardiographies, thrombi were detected in 51 patients (1.2\%) and SEC in 251 patients $(6.2 \%)$. These patients formed the final study cohort $(n=302)$. During a mean follow-up period of $956 \pm 663$ days, 87 patients (29\%) suffered the primary point. The following baseline characteristics predicted the primary endpoint: age, haemoglobin, a previous coronary artery bypass grafting, dialysis and choice of anticoagulation. Prescription of apixaban at discharge was associated with lower rate of adverse events (hazard ratio 0.564 , confidence interval $0.331-0.960 ; p=0.035$ ) while prescription of dabigatran was associated with higher rate of adverse events (hazard ratio 3.091, confidence interval $1.506-6.347 ; p=0.002$ ).
\end{abstract}

Conclusion Even in the DOAC era, the occurrence of thrombus or SEC in the LAA is associated with a high rate of MACCE. Our study suggests that the choice of DOAC therapy may have an impact on long-term survival.

Michael Gotzmann

michael.gotzmann@rub.de

1 Cardiology and Rhythmology, University Hospital St.

Josef Hospital, Ruhr-University Bochum, Gudrunstraße 56,

44791 Bochum, Germany

2 Neurology, St. Josef-Hospital, Ruhr-University Bochum, Gudrunstraße 56, 44791 Bochum, Germany 


\section{Graphic abstract}

\section{Thrombus/spontaneous echo contrast in the left atrial appendage}

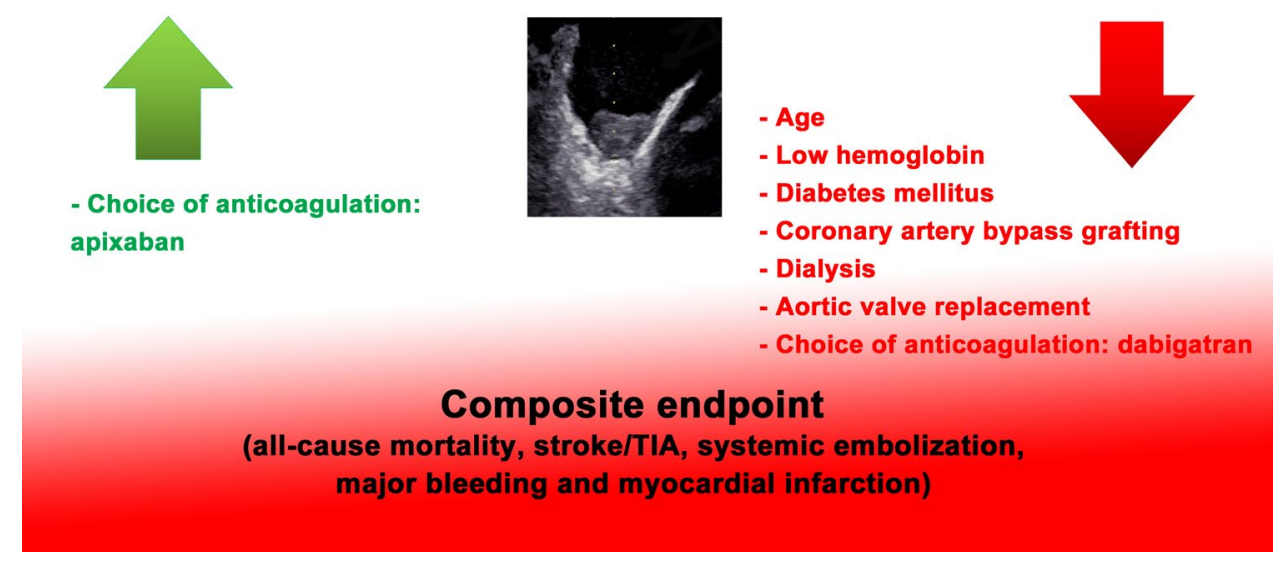

Keywords Thrombi and spontaneous echo contrast $\cdot$ Outcome $\cdot$ Direct acting anticoagulants

$\begin{array}{ll}\text { Abbreviations } \\ \text { AF } & \text { Atrial fibrillation } \\ \text { LAA } & \text { Left atrial appendage } \\ \text { MACCE } & \begin{array}{l}\text { Major adverse cardiac and cerebrovascular } \\ \text { events }\end{array} \\ \text { DOAC } & \begin{array}{l}\text { Direct acting anticoagulants } \\ \text { SEC }\end{array} \\ \text { Spontaneous echo contrast } \\ \text { TIA } & \text { Transient ischaemic attack } \\ \text { VKA } & \text { Vitamin K antagonist }\end{array}$

\section{Introduction}

Thrombi and spontaneous echo contrast (SEC) in the left atrial appendage (LAA) are relatively common findings on transesophageal echocardiography [1]. Both abnormalities are associated with thromboembolism and poor prognosis [2-7]. Thrombi and SEC in the LAA occur predominantly in atrial fibrillation (AF) but have also been described in patients without AF [8].

The detection of a thrombus in the LAA is usually an indication for therapeutic anticoagulation [9]. In contrast, in the case of an SEC, the recommendation for anticoagulants is only given in the case of corresponding pre-existing conditions (predominantly atrial fibrillation with increased thromboembolic risk) [10]. About 10 years ago, the direct acting anticoagulants (DOACs) were introduced for the prophylaxis of thromboembolic events in patients with $\mathrm{AF}$ [11-14]. Despite the partial lack of data from prospective randomised controlled trials [15], DOACs are used in many centers for the treatment of thrombi in the LAA [16].
However, there are few data on the long-term outcome of patients with thrombus or SEC in the LAA on anticoagulation. In particular, there are very scarce studies on anticoagulation with DOAC in this group of patients [17-19].

Therefore, the aims of this study were (1) to investigate the prevalence of thrombus and SEC in the LAA in the DOAC era, (2) to analyze the long-term outcome in terms of death, stroke, major bleeding, systemic embolization, and myocardial infarction of patients with thrombus and SEC, and (3) to investigate the impact of anticoagulation on eventfree long-term survival.

\section{Methods}

This study examined all patients in the years 2015 to 2020 in whom a thrombus or SEC was detected in LAA on transoesophageal echocardiography. All examinations were performed at the St. Josef Hospital-Hospital of the Ruhr University Bochum. The indications for transoesophageal echocardiography were as follows: planned electrical or pharmacological cardioversion, prior to pulmonary vein isolation or ventricular tachycardia ablation, prior to left atrial appendage occlusion, in cases of cryptogenic stroke, TIA or other thromboembolic events, for evaluation of heart valves, unclear infection or suspected aortic dissection. Patients gave informed consent.

Medical history, laboratory examinations (creatinine and hemoglobin), echocardiography results, medication before and after transoesophageal echocardiography were recorded for all patients. This study is a retrospective 
analysis. The study was approved by the local ethics committee of the Ruhr University Bochum (Number 21-7234-BR).

\section{Inclusion and exclusion criteria and endpoint}

For this study, we examined retrospectively all transoesophageal echocardiographies performed between 2015 and 2020. All patients in whom a thrombus or a SEC in the LAA was detected were included in this analysis. Patients with thrombi in other cardiac cavities, cardiac tumours and previous interventional or surgical occlusion of the LAA were excluded.

The primary endpoint of the study was a composite endpoint (all-cause mortality, non-fatal stroke or transient ischaemic attack [TIA], non-fatal systemic embolization, non-fatal major bleeding and non-fatal myocardial infarction). Major bleeding was defined according to the Bleeding Academic Research Consortium criteria as BARC $\geq 3$ [20]. For the analyses of the combined primary endpoint, the time to the occurrence of the first adverse event was considered. Secondary study endpoint was all-cause mortality. We obtained the follow-up information based on outpatient and inpatient admissions. In addition, a followup was performed in 2021, either in personal or telephone contact or with the deceased patients' general practitioners.

\section{Echocardiography}

Transthoracic echocardiography was performed within 7 days before transoesophageal echocardiography. Both examinations were conducted with a digital ultrasound scanner (Vivid E9; General Electric, Horton, Norway). Transoesophageal echocardiography was performed by experienced examiners according to current recommendations [21].

A thrombus in the LAA was defined as a solid echo-dense structure detectable in multiple imaging planes in the LAA [22]. If a thrombus was detected, transoesophageal echocardiography was repeated at least 3 weeks after the initial examination [9].

SEC in the LAA was diagnosed with evidence of swirling dynamic echoes without evidence of thrombus. In accordance with the EACVI/EHRA recommendation, SEC was classified as mild to moderate SEC (swirling pattern in the LAA), severe SEC (intense echo-density and very slow swirling patterns in the LAA) and sludge (dense smoke, viscid echo-density, not solid) [1]. These patients underwent no routine repeated transoesophageal echocardiography. In the case of simultaneous occurrence of thrombus and SEC in the LAA, only the thrombus was assessed for the calculations.

\section{Anticoagulation}

Anticoagulation was continued or initiated in all patients in whom a thrombus was detected. Patients who had not previously received anticoagulation were given intravenous heparin immediately. In patients on vitamin $\mathrm{K}$ antagonist (VKA) therapy with effective INR values or on DOAC therapy, this therapy was continued or changed according to the clinical decision of the treating physician.

In patients with SEC, anticoagulation was prescribed if the patient had AF with a CHADS-VASc score of $\geq 1$ or if there were other reasons for anticoagulation (e.g. mechanical valve replacement, pulmonary embolism or deep vein thrombosis). Acetylsalicylic acid and P2Y12 inhibitors and combinations were used due to patient comorbidities and not directly for thrombus or SEC therapy. The documented anticoagulation medication reflects the medication at the time of discharge after initial transoesophageal echocardiography.

\section{Statistics}

Numerical values are expressed as mean \pm standard deviation. Continuous variables were compared between groups using an unpaired $t$ test (for normally distributed variables) or Mann-Whitney U test (for non-normally distributed variables). $\chi^{2}$ analysis was used to compare categoric variables. All variables in Tables 1, 2 and 3 were evaluated for the primary end point and all variables in Tables supplement 1,2 and 3 were evaluated for the secondary endpoint in a univariate and multivariate Cox proportional hazard model to identify independent predictors of outcome. Receiver operating characteristic curves were generated to define cutoff values for independent predictors' age and hemoglobin. Results are present as hazard risk. Freedom from primary and secondary endpoints was analyzed by the Kaplan-Meier method and curves were compared by the log-rank test. A $P$ value $<0.05$ was considered significant. All probability values reported are 2-sided.

\section{Results}

Between 2015 and 2020, 4062 transoesophageal echocardiographies were performed at St-Josef-Hospital Bochum. In 51 patients (1.2\%) thrombi in the LAA was found and SEC in the LAA in 251 patients (6.2\%). SEC was mild to moderate in 194 patients, severe in 52 patients and sludge was present in 5 patients. Of the 51 patients with thrombus, a total of 22 patients also had some degree of SEC. These patient subgroups did not differ in baseline characteristics or outcome. The patients with thrombus or SEC in the LAA formed the final study $(n=302)$ cohort. The mean age of the patients ( $44 \%$ women, $56 \%$ men) was $72 \pm 9.7$ years (minimum 
Table 1 Baseline

Characteristics in patients with and without a primary endpoint $(n=302)$

Table 2 Transthoracic and transoesophageal echocardiographic parameters of study patients $(n=302)$

\begin{tabular}{lllr}
\hline & $\begin{array}{l}\text { Primary endpoint } \\
(n=87)\end{array}$ & $\begin{array}{l}\text { No primary endpoint } \\
(n=215)\end{array}$ & $p$ value \\
\hline Age (years) & $75.1 \pm 7.6$ & $70.7 \pm 10.2$ & $<0.001$ \\
Women (\%), $n(\%)$ & $38(44)$ & $95(44)$ & 0.936 \\
Medical history & & & \\
Hypertension, $n(\%)$ & $81(93)$ & $195(91)$ & 0.500 \\
Diabetes mellitus, $n(\%)$ & $39(45)$ & $55(26)$ & 0.001 \\
Atrial fibrillation, $n$ (\%) & $82(94)$ & $209(97)$ & 0.214 \\
Coronary artery disease, $n(\%)$ & $37(43)$ & $61(28)$ & 0.017 \\
Previous myocardial infarction, $n(\%)$ & $14(16)$ & $26(12)$ & 0.353 \\
Coronary artery bypass grafting, $n(\%)$ & $13(15)$ & $5(2)$ & $<0.001$ \\
Previous stroke/TIA, $n(\%)$ & $24(28)$ & $34(16)$ & 0.020 \\
Peripheral artery disease, $n(\%)$ & $17(20)$ & $24(11)$ & 0.054 \\
Chronic obstructive lung disease, $n(\%)$ & $12(14)$ & $21(10)$ & 0.310 \\
Heart failure, $n(\%)$ & $40(46)$ & $61(28)$ & 0.003 \\
ICD/CRT, $n(\%)$ & $12(14)$ & $8(4)$ & 0.001 \\
Dialysis, $n$ (\%) & $6(7)$ & 0 & $<0.001$ \\
CHA2DS2-VASc Score (pts) & $4.75 \pm 1.67$ & $3.69 \pm 1.71$ & $<0.001$ \\
Labor & & & $<0.001$ \\
Hemoglobin (g/dL) & $12.4 \pm 2.3$ & $13.8 \pm 1.8$ & 0.002 \\
Creatinine (mg/dL) & $1.33 \pm 1.2$ & $1.05 \pm 0.35$ & \\
\hline
\end{tabular}

$T I A$ transient ischaemic attack, ICD/CRT implantable cardioverter defibrillator/cardiac re-synchronisation therapy

\begin{tabular}{llll}
\hline & $\begin{array}{l}\text { Primary end- } \\
\text { point }(n=87)\end{array}$ & $\begin{array}{l}\text { No primary end- } \\
\text { point }(n=215)\end{array}$ \\
\hline Left ventricular ejection fraction (\%) & $47.7 \pm 12.1$ & $48.5 \pm 11.6$ & 0.579 \\
Left atrial diameter (mm) & $45.3 \pm 6$ & $43.9 \pm 5.4$ & 0.064 \\
Ventricular septum thickness (mm) & $12.6 \pm 2.1$ & $12.2 \pm 2$ & 0.155 \\
Left atrial appendage thrombus, $n$ (\%) & $20(23)$ & $31(14)$ & 0.072 \\
Spontaneous echo contrast (mild to moderate, severe, sludge) & $47 / 17 / 3$ & $147 / 35 / 2$ & 0.111 \\
Aortic stenosis (none/ mild/ moderate/ severe), $n$ & $81 / 2 / 2 / 2$ & $204 / 3 / 3 / 5$ & 0.808 \\
Aortic regurgitation (none/ mild/ moderate/ severe), $n$ & $42 / 42 / 1 / 2$ & $126 / 82 / 2 / 0$ & 0.063 \\
Mitral stenosis (none/ mild/ moderate/ severe), $n$ & $85 / 1 / 1 / 0$ & $208 / 4 / 1 / 2$ & 0.696 \\
Mitral regurgitation (none/ mild/ moderate/ severe), $n$ & $6 / 71 / 8 / 2$ & $23 / 155 / 36 / 1$ & 0.216 \\
Tricuspid regurgitation (none/ mild/ moderate/ severe), $n$ & $22 / 48 / 14 / 3$ & $75 / 120 / 17 / 3$ & 0.068 \\
Aortic valve replacement/TAVI, $n$ (\%) & $7(8)$ & $4(2)$ & 0.009 \\
Mitral valve repair/ replacement $n(\%)$ & $3(3)$ & $7(3)$ & 0.933 \\
\hline
\end{tabular}

$T A V I$ trans-aortic valve implantation
40 years, maximum 91 years). The mean left ventricular ejection fraction was $48.3 \pm 11.8 \%$ and the CHA2DS2-VASc score was $4 \pm 1.8$ points.

The indications for transoesophageal echocardiography in the study cohort were planned electrical $(n=210)$ or pharmacological $(n=2)$ cardioversion, prior to pulmonary vein isolation or ventricular tachycardia ablation $(n=27)$, prior to interventional left atrial appendage occlusion $(n=3)$, in cases of cryptogenic stroke, TIA or other thromboembolic events $(n=26)$, for evaluation of heart valves $(n=9)$, unclear infection $(n=18)$ and other indications $(n=7)$.

Patients with thrombus had a significantly lower left ventricular ejection fraction than patients with SEC $(45 \pm 12.4$ vs. $49 \pm 11.5, p=0.032$ ). Otherwise, there were no significant differences between the two subgroups of patients-in particular, there was no difference in left atrial diameter or CHA2DS2-VASc score. 
Table 3 Medication at discharge after initial transoesophageal echocardiography of study patients $(n=302)$

\begin{tabular}{lllr}
\hline & $\begin{array}{l}\text { Primary } \\
\text { endpoint } \\
(n=87)\end{array}$ & $\begin{array}{l}\text { No primary } \\
\text { endpoint } \\
(n=215)\end{array}$ & $p$ value \\
\hline Acetylsalicylic acid, $n(\%)$ & $20(23)$ & $37(17)$ & 0.245 \\
P2Y12-Inhibitor, $n(\%)$ & $2(2)$ & $14(7)$ & 0.139 \\
Dual therapy*, $n(\%)$ & $14(16)$ & $25(12)$ & 0.295 \\
Triple therapy*, $n(\%)$ & 0 & $10(5)$ & 0.041 \\
Vitamin K antagonist, $n$ & $34(39)$ & $63(29)$ & 0.099 \\
$(\%)$ & & $110(51)$ & $<0.001$ \\
Apixaban, $n(\%)$ & $21(24)$ & $9(4)$ & 0.018 \\
Dabigatran, $n(\%)$ & $10(11)$ & $13(6)$ & 0.783 \\
Edoxaban, $n(\%)$ & $6(7)$ & $12(6)$ & 0.219 \\
Rivaroxaban, $\mathrm{n}(\%)$ & $2(2)$ & $4(2)$ & 0.003 \\
Heparine, $n(\%)$ & $8(9)$ & $4(2)$ & 0.027 \\
No anticoagulation, $n(\%)$ & $6(7)$ & & \\
\hline
\end{tabular}

*Dual therapy, combination of Acetylsalicylic acid/P2Y12 and $\mathrm{DOAC} / \mathrm{Vitamin} \mathrm{K}$ antagonist, *Triple therapy, combination of Acetylsalicylic acid, P2Y12 and DOAC/ Vitamin K antagonist. DOAC and a Vitamin $\mathrm{K}$ antagonist are not used concomitantly

Of the study patients, 291 patients (96\%) had known AF or AF were diagnosed during hospitalisation (paroxysmal [ $n=29$ ], persistent [241], permanent [ $n=21])$. The remaining 11 patients (4\%) had sinus rhythm and AF was neither known nor diagnosed. Of these, 3 patients presented with a thrombus and 8 patients with SEC.

\section{Treatment of patients with thrombus}

Patients with thrombus detection were taking the following anticoagulation prior to transoesophageal echocardiography: no anticoagulation $(n=27)$, apixaban $(n=12)$, VKA (phenprocoumon) $(n=8)$, rivaroxaban $(\mathrm{n}=3)$, heparin $(n=1)$. In some cases, medication was changed after transoesophageal echocardiography. All patients with detected thrombus received anticoagulation-either VKA, DOAC or heparin in therapeutic dosage. Most patients with thrombus received at discharge VKA therapy with a target INR of $2-3(n=25)$. Other medication for anticoagulation were: Apixaban $(n=16)$, Dabigatran $(n=6)$, Rivaroxaban $(n=1)$ and Heparin $(n=3)$. Of the 51 patients with thrombus in the LAA, 40 underwent repeated transoesophageal echocardiography in our hospital. In these examinations, a persistent thrombus was found in 10 patients, while the thrombus had vanished in the remaining 30 patients in the control. Of the remaining 11 patients without repeat transoesophageal echocardiography, 3 died within the first 30 days and in 8 patients, no control examination was performed.

\section{Treatment of patients with SEC}

Patients with SEC received the following anticoagulation medication before transoesophageal echocardiography: no anticoagulation $(n=97)$, apixaban $(n=60)$, VKA $(n=51)$, rivaroxaban $(n=12)$, dabigatran $(n=6)$, edoxaban $(n=12)$ and heparin $(n=13)$. Detection of SEC usually did not lead to a change in anticoagulation. However, other conditionsparticularly the initial diagnosis of AF-led to anticoagulant prescriptions. At discharge, patients with SEC were receiving the following anticoagulants: apixaban $(n=115)$, VKA $(n=72)$, rivaroxaban $(n=13)$, dabigatran $(n=13)$, edoxaban $(n=19)$, heparin $(n=9)$ and no anticoagulation $(n=10)$.

\section{Reduced dose of DOAC}

At the time of discharge, the dose of DOAC was chosen according to the current recommendation. The reduced dose was prescribed for relevant comorbidities [23]. Of the 302 study patients, a total of 131 patients received apixaban (reduced dose: $2 \times 2.5 \mathrm{mg}, \mathrm{n}=18$ ), 19 patients received dabigatran (reduced dose: $2 \times 110 \mathrm{mg}, n=8$ ), 19 patients received edoxaban (reduced dose: $1 \times 30 \mathrm{mg}, n=7$ ), and 14 patients received rivaroxaban (reduced dose: $1 \times 15 \mathrm{mg}$, $n=0)$.

\section{Patients receiving no anticoagulation or heparin}

Of the 302 study patients, a total of 10 patients (3\%) with SEC did not receive anticoagulation. Three patients underwent implantation of an interventional LAA occluder and initiation of dual antiplatelet therapy. In another 3 patients with mild to moderate SEC, sinus rhythm was present without evidence of AF. Individual factors were present in the remaining patients: gastrointestinal varices, tumor disease, severe wound healing disorder and refusal of anticoagulation therapy.

In total, 12 patients (4\%) received therapy only with heparin. Of these, 5 patients received only a prophylactic dose and 7 patients received a therapeutic dose of low molecular weight or unfractionated heparin. The decision to provide heparin therapy was due to concomitant conditions: immediately planned surgery $(n=4)$, prolonged treatment in the intensive care unit with subsequent death $(n=3)$, recurrent bleeding $(n=1)$, active tumor disease $(n=1)$, refusal of oral anticoagulation for dementia $(n=1)$ and sinus rhythm without thrombus $(n=2)$.

\section{Adverse events}

The following adverse events occurred in the study population during the entire observation period: (1) Fatal events: Death from any cause $(n=70)$. The causes of death were 
stroke $(n=5)$, myocardial infarction $(n=2)$, heart failure $(n=7)$, sudden cardiac death $(n=4)$, acute vascular occlusion $(n=1)$, tumour disease $(n=3)$, renal failure $(n=2)$, sepsis $(n=10)$ and unclear or multiple causes $(n=36)$. 2$)$ In addition, the following non-fatal events occurred: nonfatal stroke/TIA ( $n=16$; of which ischaemic stroke, $n=15$, intracerebral bleeding $n=1)$, non-fatal embolisation $(n=2)$, non-fatal severe bleeding $n=10$; of which gastrointestinal bleeding, $n=6$, intracerebral bleeding $n=1$, other $n=3$ ), non-fatal myocardial infarction $(n=1)$.

\section{Primary endpoint}

During a mean follow-up period of $956 \pm 663$ days, 87 patients (29\%) suffered the primary point (composite endpoint of all-cause mortality $[n=61]$, non-fatal stroke or TIA [ $n=16]$, non-fatal systemic embolization $[n=1]$, non-fatal major bleeding $[n=8]$ and non-fatal myocardial infarction $[n=1])$. Clinical characteristics, echocardiographic parameters, and medication at discharge are listed in Tables 1, 2 and 3. Table 4 lists all parameters that were significantly associated with the occurrence of primary endpoint in the long-term course. Notably, the occurrence of thrombus in the LAA was associated with a significantly higher rate of primary endpoint in the long-term outcome (Fig. 1).

Independent parameters for the occurrence of primary endpoint in the long-term course were age, haemoglobin, diabetes mellitus, a previous coronary artery bypass grafting, dialysis and use of dabigatran and apixaban. Prescription of dabigatran at discharge was associated with higher

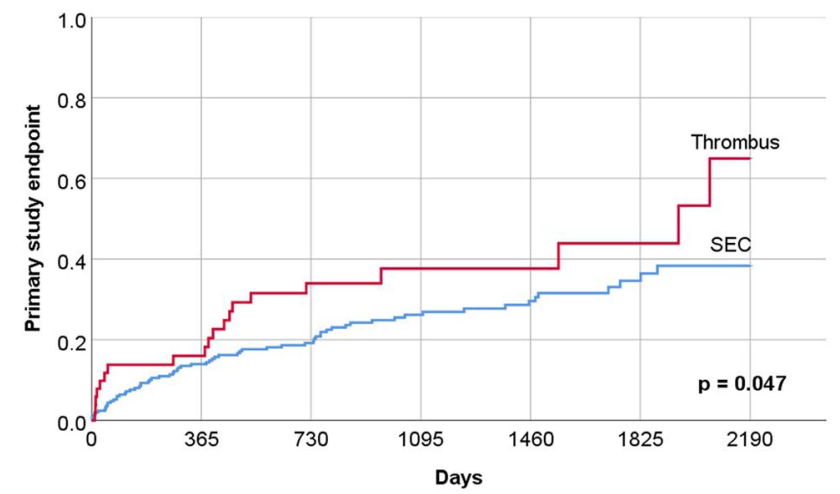

Fig. 1 Short- and long-term outcome (primary endpoint) in study patients according to presence of thrombus or spontaneous echo contrast in left atrial appendage

rate of primary endpoint while prescription of apixaban was associated with a lower rate of primary endpoint (Table 4).

Using receiver operating characteristic analysis, cutoff values for separating study patients were age $\geq 70$ years (area under the curve [AUC] 0.614, CI 0.547-0.618, $p=0.001$; hazard ratio 2.176, confidence interval 1.308-3.623; $p=0.003$ ) and hemoglobin $<12 \mathrm{mg} / \mathrm{dl}$ (AUC 0.683, CI $0.617-0.750, p<0.001$; hazard ratio 3.823 , confidence interval 2.464-5.933; $p<0.001)$.

Kaplan-Meier curves were generated for primary endpoint based on the anticoagulation prescribed at the time of discharge (VKA, apixaban, dabigatran, edoxaban, rivaroxaban, heparin and no anticoagulation). This revealed

Table 4 Univariate und multivariate analysis: predictors of long-term outcome

\begin{tabular}{|c|c|c|c|c|c|c|}
\hline & \multirow[b]{2}{*}{ Hazard ratio } & \multicolumn{2}{|l|}{ Univariate analysis } & \multirow[b]{2}{*}{ Hazard ratio } & \multicolumn{2}{|l|}{ Multivariate analysis } \\
\hline & & Confidence interval & $p$ value & & Confidence interval & $p$ value \\
\hline Age (years) & 1.054 & $1.027-1.082$ & $<0.001$ & 1.036 & $1.006-1.066$ & 0.019 \\
\hline Hemoglobin (g/dL) & 0.699 & $0.634-0.772$ & $<0.001$ & 0.762 & $0.682-0.852$ & $<0.001$ \\
\hline Creatinine (mg/dL) & 1.939 & $1.573-2.390$ & $<0.001$ & & & \\
\hline CHA2DS2-VASc Score (pts) & 1.374 & $1.217-1.551$ & $<0.001$ & & & \\
\hline Diabetes mellitus & 2.092 & $1.367-3.200$ & 0.001 & 1.628 & $1.012-2.618$ & 0.044 \\
\hline Heart failure & 1.991 & $1.305-3.036$ & 0.001 & & & \\
\hline Coronary artery disease & 1.607 & $1.050-2.459$ & 0.029 & & & \\
\hline Coronary artery bypass grafting & 4.252 & $2.344-7.712$ & $<0.001$ & 2.861 & $1.488-5.504$ & 0.002 \\
\hline Previous stroke/TIA & 2.074 & $1.294-3.324$ & 0.002 & & & \\
\hline Dialysis & 19.713 & $8.056-48.235$ & $<0.001$ & 6.446 & $1.775-23.409$ & 0.005 \\
\hline Aortic valve replacement & 3.266 & $1.505-7.088$ & 0.003 & 2.394 & $1.052-5.449$ & 0.037 \\
\hline $\mathrm{ICD} / \mathrm{CRT}$ & 3.521 & $1.903-6.514$ & $<0.001$ & & & \\
\hline Heparine & 6.514 & $3.090-13.730$ & $<0.001$ & & & \\
\hline Apixaban & 0.411 & $0.251-0.673$ & $<0.001$ & 0.564 & $0.331-0.960$ & 0.035 \\
\hline Dabigatran & 2.624 & $1.353-5.088$ & 0.004 & 3.091 & $1.506-6.347$ & 0.002 \\
\hline No anticoagulation & 3.900 & 1.689-9.009 & 0.001 & & & \\
\hline
\end{tabular}

TIA transient ischaemic attack, ICD/CRT implantable cardioverter defibrillator/cardiac re-synchronisation therapy 


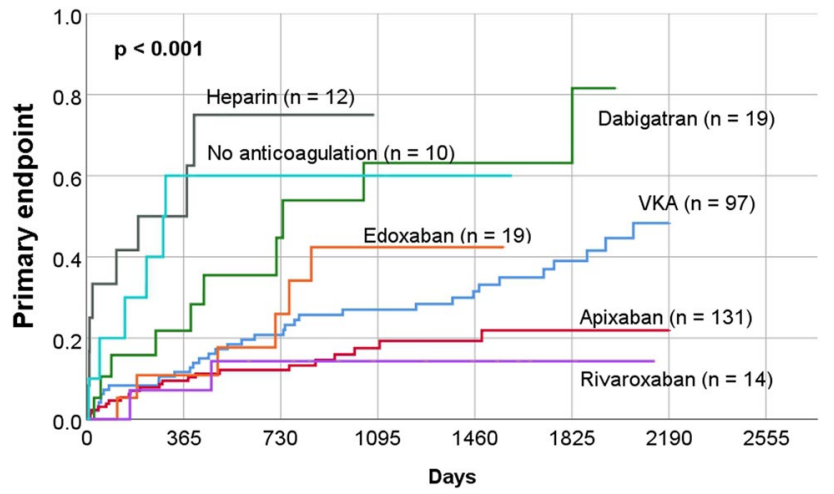

Fig. 2 Long-term outcome (primary endpoint) in the study patients according to oral anticoagulation at the time of discharge after initial transoesophageal echocardiography

a significant difference in the rates of primary endpoint between groups $(p<0.001)$ (Fig. 2).

\section{Secondary endpoint}

During a mean follow-up period of $1002 \pm 669$ days, 70 patients (23\%) suffered the secondary endpoint (all-cause mortality). Clinical characteristics, echocardiographic parameters, and medications are listed in tables (Tables Supplement 1, 2 and 3). Table Supplement 4 lists all parameters that were significantly associated with the secondary study endpoint. Multivariate analysis showed that the parameters age, haemoglobin, creatinine, previous coronary artery bypass grafting, tricuspid regurgitation and use of apixaban were independently associated with the occurrence of secondary endpoint (Table Supplement 4). Kaplan-Meier curves were also generated for secondary endpoint based on the anticoagulation prescribed at the time of discharge. This revealed a significant difference in the rates of secondary endpoint between groups $(\mathrm{p}<0.001)$ (Fig. 3).

\section{Subgroup analysis}

In a subgroup analysis, we examined how dose reduction of DOAC affected rates of adverse events (primary endpoint). Figure 1 in the supplements illustrates the Kaplan-Meier curves of all patients who received a DOAC at discharge, either at the standard or reduced dose. Again, there were significant differences between the groups $(p<0.001)$ (Fig. 4).

In a further subgroup analysis, only patients with $\mathrm{AF}$ without valve replacement and valve repair or mitral stenosis were included ("non-valvular AF"). The anticoagulation of the remaining 267 patients was also analyzed by Kaplan-Meier curves. Furthermore, there was a significant difference in patients`outcome $(p<0.001)$ (Fig. 5).

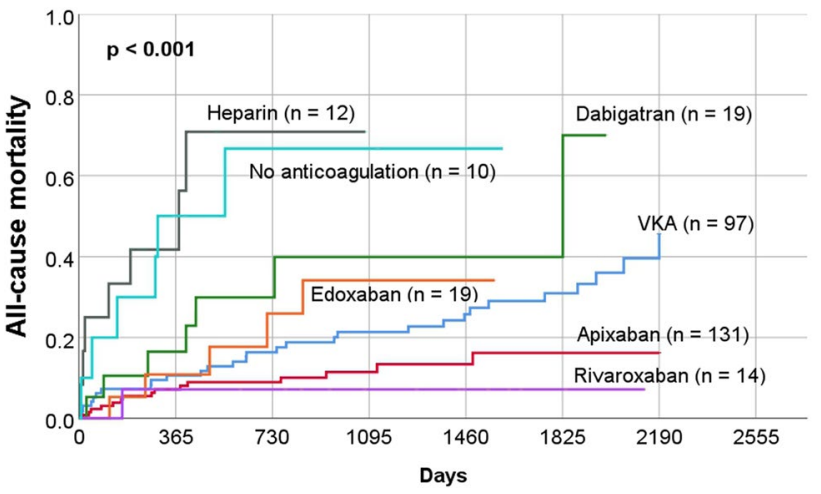

Fig. 3 All-cause mortality (secondary endpoint) of the study patients according to oral anticoagulation at the time of discharge after initial transoesophageal echocardiography

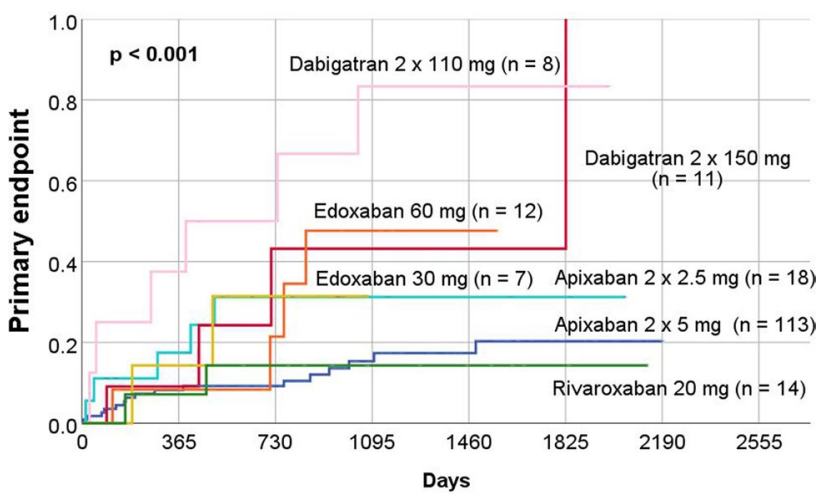

Fig. 4 Long-term outcome (primary endpoint) in the study patients according to standard or reduced dose of oral anticoagulation at the time of discharge after initial transoesophageal echocardiography

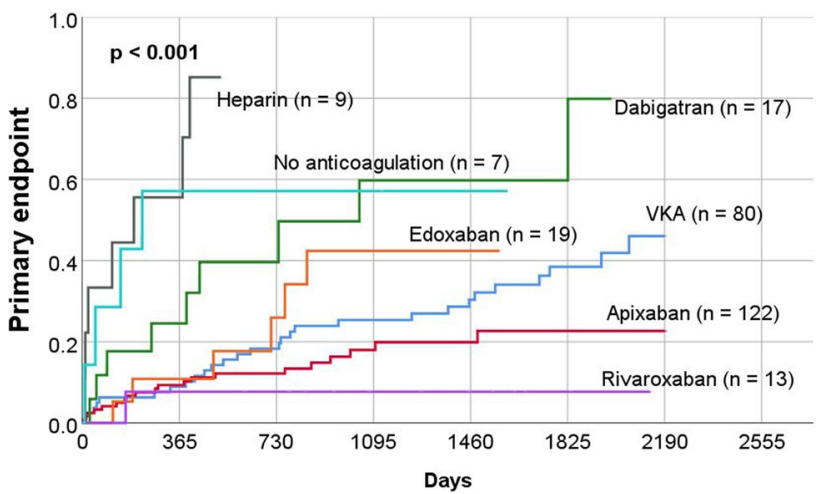

Fig. 5 Long-term outcome (primary endpoint) subgroup of study patients with non-valvular atrial fibrillation according oral anticoagulation at the time of discharge after initial transoesophageal echocardiography 


\section{Discussion}

The present study investigated the outcome of patients with evidence of thrombus or SEC in the LAA on transoesophageal echocardiography in the era of DOAC. The study has several main findings. First, it should be noted that patients with thrombus did not differ significantly in clinical and echocardiographic characteristics compared with patients with SEC-except for left ventricular ejection fraction. The clinical outcome of patients with thrombus or SEC is similar, although patients with thrombus have a significantly higher event rate than patients with SEC (Fig. 1).

Independent factors for the occurrence of adverse events (primary endpoint: composite endpoint of all-cause mortality, non-fatal stroke or TIA, non-fatal systemic embolization, non-fatal major bleeding, and non-fatal myocardial infarction) in the long-term follow-up were age, haemoglobin, previous coronary artery grafting, dialysis and choice of anticoagulation.

\section{Incidence of thrombus and SEC in the LAA in the DOAC era}

The exact prevalence of thrombi and SEC in the LAA is unclear. In a meta-analysis by Di Minno et al., the prevalence of thrombi in the left atrium including the LAA was described to be approximately $10 \%$ in patients with nonvalvular AF [24]. In a review by Patel et al., a frequency of SEC in patients with AF was reported to be $12-67 \%$ [25]. In contrast to the above publications, Vinereanu et al. reported a prevalence of $2 \%$ of thrombi and SEC in the left atrium on baseline echocardiography in a subgroup analysis of ARISTOTLE [17]. Recently, in a prospective multicenter registry of 6186 patients with AF undergoing radiofrequency catheter ablation on uninterrupted DOAC, no thrombus was detected on transoesophageal echocardiography, but SEC was detected in 27\% [25]. By contrast, Wu et al. reported an incidence of $2.8 \%$ thrombi and $2.5 \%$ dense SEC in a similar study population with DOAC anticoagulated patients [26].

In our study, thrombus and SEC in the LAA were detected in $1.2 \%$ and $6.2 \%$, respectively, of all transoesophageal echocardiographies that were performed in our hospital between 2015 and 2020. This means that in every 15th transoesophageal echocardiography, a finding associated with increased risk of stroke and poor prognosis was detected [2-7]. It is worth mentioning that in our study, anticoagulation with a DOAC was already used in one third of all patients when thrombi or SEC were detected. On the other hand, approximately $40 \%$ of all patients were not taking anticoagulation previously and the remaining patients were treated with VKA or heparin. It can be assumed that the proportion of DOAC will continue to increase in the future.

Impact of anticoagulation on event-free long-term survival.

Until recently, European guidelines recommended the use of vitamin $\mathrm{K}$ antagonists for at least 3 weeks to dissolve thrombi in the LAA and long-term therapy for persistent thrombin [27]. In the last years, first case reports and later smaller studies were published suggesting the usage of NOAC as a possible therapeutic option for thrombi or SEC [15].

Two prospective, multicentre trials demonstrated that rivaroxaban is effective in the treatment of LAA and left atrial thrombi. However, no long-term results were reported $[18,19]$. In a subgroup analysis of the ARISTOTLE study, it was reported that patients on effective anticoagulation with apixaban or warfarin had no increased risk of thromboembolic events even in the presence of thrombi or SEC in the LAA [17].

Our study revealed differences in outcome according to the choice of anticoagulation (Figs. 2, 3 and 5). The use of heparin alone for anticoagulation was associated with worse outcome. This result can be explained by the fact that those medicated only with heparin were often patients who were seriously ill and treated in the intensive care unit for a longer period. Similarly, the non-anticoagulated group is heterogeneous and partly burdened with considerable comorbidities, which also explains the increased rate of events.

The multivariate analysis demonstrated that the prescription of apixaban at discharge was an independent factor for a lower rate of adverse events (Table 4). The group of patients prescribed rivaroxaban also had a low rate of adverse events. However, this subgroup included only a few patients, so there were no significant differences.

Similarly, the subgroup of patients who were prescribed edoxaban or dabigatran at discharge was small. Furthermore, it should be noted that our study was not able to investigate changes in oral anticoagulation or patient compliance. The results must therefore be interpreted with caution. Nevertheless, our study suggests that the use of dabigatran in patients with thrombi or SEC in the LAA may be unfavourable in the long-term. The observed differences in outcome may be explained by the different effects of the drugs [28].

\section{Limitations}

The main limitation of the present study is the retrospective and monocentric character of the study. Therefore, it has not been feasible to evaluate the patients in terms of atrial hemodynamics or laboratory parameters, which may also have influenced the outcome. The choice of anticoagulation 
or further therapy (e.g. pulmonary vein isolation, cardioversion, interventional LAA closure, etc.) was at the discretion of the treating physicians and was not defined by a study protocol. This may have biased the study results. On the other hand, the approach described here may be more in line with clinical routine. In our study, we were also unable to investigate changes in prescribed anticoagulation or patient compliance. This may be particularly important in the long term. Furthermore, the subgroups of the different anticoagulants (in particular edoxaban, dagibatran and rivaroxaban) are partly small. The results of the present study with respect to the choice of anticoagulation should therefore be evaluated with caution. Nevertheless, the present study is the largest study that has ever investigated the long-term outcome of patients with thrombus and SEC in the LAA under different anticoagulants.

\section{Conclusion}

Even in the era of DOAC, thrombus or SECs are detected in the LAA in more than $7 \%$ of all trans-esophageal echocardiographies. In the short term, the clinical outcome of patients with thrombus and SEC is poor, with thrombus being associated with a slightly more frequent proportion of adverse advents. Moreover, our study suggests that differences in the long-term outcome may depend on the choice of anticoagulation.

Supplementary Information The online version contains supplementary material available at https://doi.org/10.1007/s00392-021-01926-8.

Funding Open Access funding enabled and organized by Projekt DEAL.

\section{Declarations}

Conflict of interest Dr. Gotzmann was a speaker for Abbott, BristolMyers Squibb, Novartis and Pfizer. Dr. Krogias received traval grants and speaker honoraria from Bayer Vital and Daiichi-Sankyo.

Ethics approval statement The study was approved by the local ethics committee of the Ruhr University Bochum (Number 21-7234-BR).

Open Access This article is licensed under a Creative Commons Attribution 4.0 International License, which permits use, sharing, adaptation, distribution and reproduction in any medium or format, as long as you give appropriate credit to the original author(s) and the source, provide a link to the Creative Commons licence, and indicate if changes were made. The images or other third party material in this article are included in the article's Creative Commons licence, unless indicated otherwise in a credit line to the material. If material is not included in the article's Creative Commons licence and your intended use is not permitted by statutory regulation or exceeds the permitted use, you will need to obtain permission directly from the copyright holder. To view a copy of this licence, visit http://creativecommons.org/licenses/by/4.0/.

\section{References}

1. Donal E, Lip GY, Galderisi M, Goette A, Shah D, Marwan M, Lederlin M, Mondillo S, Edvardsen T, Sitges M, Grapsa J, Garbi M, Senior R, Gimelli A, Potpara TS, Van Gelder IC, Gorenek B, Mabo P, Lancellotti P, Kuck KH, Popescu BA, Hindricks G, Habib G, Cardim NM, Cosyns B, Delgado V, Haugaa KH, Muraru D, Nieman K, Boriani G, Cohen A (2016) EACVI/EHRA Expert Consensus Document on the role of multi-modality imaging for the evaluation of patients with atrial fibrillation. Eur Heart J Cardiovasc Imaging 17(4):355-383. https://doi.org/10.1093/ehjci/ jev354 (Epub 2016 Feb 9 PMID: 26864186)

2. Leung DY, Black IW, Cranney GB, Hopkins AP, Walsh WF (1994) Prognostic implications of left atrial spontaneous echo contrast in nonvalvular atrial fibrillation. J Am Coll Cardiol 24(3):755-762. https://doi.org/10.1016/0735-1097(94)90025-6 (PMID: 8077549)

3. Stöllberger C, Chnupa P, Kronik G, Brainin M, Finsterer J, Schneider B, Slany J (1998) Transesophageal echocardiography to assess embolic risk in patients with atrial fibrillation. ELAT Study Group. Embolism in Left Atrial Thrombi. Ann Intern Med 128(8):630-638. https://doi.org/10.7326/0003-4819-1288-199804150-00004 (PMID: 9537936)

4. Zabalgoitia M, Halperin JL, Pearce LA, Blackshear JL, Asinger RW, Hart RG (1998) Transesophageal echocardiographic correlates of clinical risk of thromboembolism in nonvalvular atrial fibrillation. Stroke Prevention in Atrial Fibrillation III Investigators. J Am Coll Cardiol 31(7):1622-1626. https://doi.org/10. 1016/s0735-1097(98)00146-6 (PMID: 9626843)

5. Dawn B, Varma J, Singh P, Longaker RA, Stoddard MF (2005) Cardiovascular death in patients with atrial fibrillation is better predicted by left atrial thrombus and spontaneous echocardiographic contrast as compared with clinical parameters. J Am Soc Echocardiogr 18(3):199-205. https://doi.org/10.1016/j. echo.2004.12.003 (PMID: 15746706)

6. Bernhardt P, Schmidt H, Hammerstingl C, Lüderitz B, Omran $H$ (2005) Patients with atrial fibrillation and dense spontaneous echo contrast at high risk a prospective and serial followup over 12 months with transesophageal echocardiography and cerebral magnetic resonance imaging. J Am Coll Cardiol 45(11):1807-1812. https://doi.org/10.1016/j.jacc.2004.11.071 (PMID: 15936610)

7. Yoo J, Song D, Baek JH, Kim YD, Nam HS, Hong GR, Kim J, Lee HS, Heo JH (2016) Poor outcome of stroke patients with atrial fibrillation in the presence of coexisting spontaneous echo contrast. Stroke 47(7):1920-1922. https://doi.org/10.1161/STROK EAHA.116.013351 (Epub 2016 May 17 PMID: 27188406)

8. Omran H, Rang B, Schmidt H, Illien S, Schimpf R, Maccarter D, Kubini R, Von Der Recke G, Tiemann K, Becher H, Lüderitz B (2000) Incidence of left atrial thrombi in patients in sinus rhythm and with a recent neurologic deficit. Am Heart J 140(4):658-662. https://doi.org/10.1067/mhj.2000.109213 (PMID: 11011342)

9. Hindricks G, Potpara T, Dagres N, Arbelo E, Bax JJ, BlomströmLundqvist C, Boriani G, Castella M, Dan GA, Dilaveris PE, Fauchier L, Filippatos G, Kalman JM, La Meir M, Lane DA, Lebeau JP, Lettino M, Lip GYH, Pinto FJ, Thomas GN, Valgimigli M, Van Gelder IC, Van Putte BP, Watkins CL, ESC Scientific Document Group (2021) 2020 ESC Guidelines for the diagnosis and management of atrial fibrillation developed in collaboration with the European Association for Cardio-Thoracic Surgery (EACTS). Eur Heart J 42(5):373-498. https://doi.org/10.1093/eurheartj/ ehaa612 (PMID: 32860505)

10. Patel SV, Flaker G (2008) Is early cardioversion for atrial fibrillation safe in patients with spontaneous echocardiographic contrast? 
Clin Cardiol 31(4):148-152. https://doi.org/10.1002/clc.20172 (PMID:17763365;PMCID:PMC6653193)

11. Connolly SJ, Ezekowitz MD, Yusuf S, Eikelboom J, Oldgren J, Parekh A, Pogue J, Reilly PA, Themeles E, Varrone J, Wang S, Alings M, Xavier D, Zhu J, Diaz R, Lewis BS, Darius H, Diener HC, Joyner CD, Wallentin L, RE-LY Steering Committee and Investigators (2009) Dabigatran versus warfarin in patients with atrial fibrillation. N Engl J Med 361(12):1139-1151. https://doi. org/10.1056/NEJMoa0905561 (Epub 2009 Aug 30. Erratum in: N Engl J Med. 2010 Nov 4;363(19):1877. PMID: 19717844)

12. Patel MR, Mahaffey KW, Garg J, Pan G, Singer DE, Hacke W, Breithardt G, Halperin JL, Hankey GJ, Piccini JP, Becker RC, Nessel CC, Paolini JF, Berkowitz SD, Fox KA, Califf RM, ROCKET AF Investigators (2011) Rivaroxaban versus warfarin in nonvalvular atrial fibrillation. N Engl J Med 365(10):883-891. https://doi.org/10.1056/NEJMoa1009638 (Epub 2011 Aug 10. PMID: 21830957)

13. Granger CB, Alexander JH, McMurray JJ, Lopes RD, Hylek EM, Hanna M, Al-Khalidi HR, Ansell J, Atar D, Avezum A, Bahit MC, Diaz R, Easton JD, Ezekowitz JA, Flaker G, Garcia D, Geraldes M, Gersh BJ, Golitsyn S, Goto S, Hermosillo AG, Hohnloser SH, Horowitz J, Mohan P, Jansky P, Lewis BS, Lopez-Sendon JL, Pais P, Parkhomenko A, Verheugt FW, Zhu J, Wallentin L, ARISTOTLE Committees and Investigators (2011) Apixaban versus warfarin in patients with atrial fibrillation. N Engl J Med 365(11):981-992. https://doi.org/10.1056/NEJMoa1107039 (Epub 2011 Aug 27. PMID: 21870978)

14. Giugliano RP, Ruff CT, Braunwald E, Murphy SA, Wiviott SD, Halperin JL, Waldo AL, Ezekowitz MD, Weitz JI, Špinar J, Ruzyllo W, Ruda M, Koretsune Y, Betcher J, Shi M, Grip LT, Patel SP, Patel I, Hanyok JJ, Mercuri M, Antman EM, ENGAGE AF-TIMI 48 Investigators (2013) Edoxaban versus warfarin in patients with atrial fibrillation. N Engl J Med 369(22):2093-2104. https://doi.org/10.1056/NEJMoa1310907 (Epub 2013 Nov 19. PMID: 24251359)

15. Marsico F, Cecere M, Parente A, Paolillo S, de Martino F, Dellegrottaglie S, Trimarco B, Perrone FP (2017) Effects of novel oral anticoagulants on left atrial and left atrial appendage thrombi: an appraisal. J Thromb Thrombolysis 43(2):139-148. https://doi.org/ 10.1007/s11239-016-1421-9 (PMID: 27614756)

16. Farkowski MM, Jubele K, Marín F, Gandjbakhch E, Ptaszynski P, Merino JL, Lenarczyk R, Potpara TS (2020) Diagnosis and management of left atrial appendage thrombus in patients with atrial fibrillation undergoing cardioversion or percutaneous left atrial procedures: results of the European Heart Rhythm Association survey. Europace 22(1):162-169. https://doi.org/10.1093/europ ace/euz257 (PMID: 31501852)

17. Vinereanu D, Lopes RD, Mulder H, Gersh BJ, Hanna M, de Barros E Silva PGM, Atar D, Wallentin L, Granger CB, Alexander JH, ARISTOTLE Investigators (2017) Echocardiographic risk factors for stroke and outcomes in patients with atrial fibrillation anticoagulated with apixaban or warfarin. Stroke 48(12):3266-3273. https://doi.org/10.1161/STROKEAHA.117.017574 (Epub 2017 Oct 31. PMID: 29089455)

18. Lip GY, Hammerstingl C, Marin F, Cappato R, Meng IL, Kirsch B, van Eickels M, Cohen A, X-TRA study and CLOT-AF registry investigators (2016) Left atrial thrombus resolution in atrial fibrillation or flutter: Results of a prospective study with rivaroxaban (X-TRA) and a retrospective observational registry providing baseline data (CLOT-AF). Am Heart J 178:126-134. https://doi. org/10.1016/j.ahj.2016.05.007 (PMID: 27502860)
19. Ke HH, He Y, Lv XW, Zhang EH, Wei Z, Li JY (2019) Efficacy and safety of rivaroxaban on the resolution of left atrial/left atrial appendage thrombus in nonvalvular atrial fibrillation patients. $\mathrm{J}$ Thromb Thrombolysis 48(2):270-276. https://doi.org/10.1007/ s11239-019-01876-z (PMID: 31165950)

20. Mehran R, Rao SV, Bhatt DL, Gibson CM, Caixeta A, Eikelboom J, Kaul S, Wiviott SD, Menon V, Nikolsky E, Serebruany V, Valgimigli M, Vranckx P, Taggart D, Sabik JF, Cutlip DE, Krucoff MW, Ohman EM, Steg PG, White H (2011) Standardized bleeding definitions for cardiovascular clinical trials: a consensus report from the Bleeding Academic Research Consortium. Circulation 123(23):2736-2747. https://doi.org/10.1161/CIRCULATIO NAHA.110.009449 (PMID: 21670242)

21. Flachskampf FA, Wouters PF, Edvardsen T, Evangelista A, Habib G, Hoffman P, Hoffmann R, Lancellotti P, Pepi M, European Association of Cardiovascular Imaging Document reviewers: Erwan Donal and Fausto Rigo (2014) Recommendations for transoesophageal echocardiography: EACVI update 2014. Eur Heart J Cardiovasc Imaging 15(4):353-365. https://doi.org/10.1093/ehjci/ jeu015 (Epub 2014 Feb 19. PMID: 24554131)

22. Lowe BS, Kusunose K, Motoki H, Varr B, Shrestha K, Whitman C, Tang WH, Thomas JD, Klein AL (2014) Prognostic significance of left atrial appendage "sludge" in patients with atrial fibrillation: a new transesophageal echocardiographic thromboembolic risk factor. J Am Soc Echocardiogr 27(11):1176-1183. https://doi.org/10.1016/j.echo.2014.08.016 (Epub 2014 Sep 26 PMID: 25262162)

23. Steffel J, Verhamme P, Potpara TS, Albaladejo P, Antz M, Desteghe L, Haeusler KG, Oldgren J, Reinecke H, Roldan-Schilling V, Rowell N, Sinnaeve P, Collins R, Camm AJ, Heidbüchel H, ESC Scientific Document Group (2018) The 2018 European Heart Rhythm Association Practical Guide on the use of non-vitamin K antagonist oral anticoagulants in patients with atrial fibrillation. Eur Heart J 39(16):1330-1393. https://doi.org/10.1093/eurheartj/ ehy 136 (PMID: 29562325)

24. Di Minno MN, Ambrosino P, Dello Russo A, Casella M, Tremoli E, Tondo C (2016) Prevalence of left atrial thrombus in patients with non-valvular atrial fibrillation. A systematic review and meta-analysis of the literature. Thromb Haemost 115(3):663-677. https://doi.org/10.1160/TH15-07- (0532 Epub 2015 Nov 26. PMID: 26607276)

25. Patel K, Natale A, Yang R, Trivedi C, Romero J, Briceno D, Mohanty S, Alviz I, Natale V, Sanchez J, Della Rocca DG, Tarantino N, Zhang XD, Mohanty P, Horton R, Burkhardt D, Gopinathannair R, Joseph Gallinghouse G, Lakkireddy D, Di Biase L (2020) Is transesophageal echocardiography necessary in patients undergoing ablation of atrial fibrillation on an uninterrupted direct oral anticoagulant regimen? Results from a prospective multicenter registry. Heart Rhythm 17(12):2093-2099. https://doi. org/10.1016/j.hrthm.2020.07.017 (Epub 2020 Jul 16 PMID: 32681991)

26. Wu M, Gabriels J, Khan M, Shaban N, D'Amato S, Liu CF, Markowitz SM, Ip JE, Thomas G, Singh P, Lerman B, Patel A, Cheung JW (2018) Left atrial thrombus and dense spontaneous echocardiographic contrast in patients on continuous direct oral anticoagulant therapy undergoing catheter ablation of atrial fibrillation: Comparison of dabigatran, rivaroxaban, and apixaban. Heart Rhythm 15(4):496-502. https://doi.org/10.1016/j.hrthm. 2017.12.005 (PMID: 29605015)

27. Camm AJ, Kirchhof P, Lip GY, Schotten U, Savelieva I, Ernst S, Van Gelder IC, Al-Attar N, Hindricks G, Prendergast B, 
Heidbuchel H, Alfieri O, Angelini A, Atar D, Colonna P, De Caterina R, De Sutter J, Goette A, Gorenek B, Heldal M, Hohloser SH, Kolh P, Le Heuzey JY, Ponikowski P, Rutten FH, European Heart Rhythm Association; European Association for CardioThoracic Surgery (2010) Guidelines for the management of atrial fibrillation: the Task Force for the Management of Atrial Fibrillation of the European Society of Cardiology (ESC). Eur Heart J 31(19):2369-2429. https://doi.org/10.1093/eurheartj/ehq278 (PMID: 20802247)
28. Sadeghi N, Kahn D, Jeske W, Hoppensteadt D, Fareed J (2013) Tissue factor-mediated activation of the prothrombin complex concentrate (PCC) is differently inhibited by dabigatran, rivaroxaban, and apixaban: potential clinical implication. Clin Appl Thromb Hemost 19(6):589-599. https://doi.org/10.1177/10760 29613479819 (Epub 2013 Mar 4. PMID: 23463187) 